\title{
One-month alcohol abstinence national campaigns: a scoping review of the harm reduction benefits
}

\author{
Julia de Ternay ${ }^{1 *}$ (D), Pierre Leblanc ${ }^{2}$, Philippe Michel ${ }^{2}$, Amine Benyamina ${ }^{3,4}$, Mickael Naassila ${ }^{5}$ and \\ Benjamin Rolland $d^{1,6,7}$
}

\begin{abstract}
Over the last decade, one-month alcohol abstinence campaigns (OMACs) have been implemented within the general population in an increasing number of countries. We identified the published studies reporting data on OMACs to explore the following aspects: profile of participants, rates and factors associated with the completion of the abstinence challenge, and outcomes and harm reduction benefits in participating in the challenges. We screened 322 records, including those found in the grey literature, and reviewed 6 studies and 7 Dry July Annual Reports. Compared to non-participating alcohol users, participants were more likely to be female, have a higher income, and a higher level of education. They were heavier drinkers and were more concerned by the consequences of alcohol on health and by their health in general. Participants who achieved the one-month abstinence challenge were lower drinkers and more likely to have registered on the campaign-related Internet communities. Both successful and unsuccessful participants frequently reported health benefits, including sleep improvement and weight loss. Successful participants were more likely to durably change their alcohol drinking habits. Overall, OMACs provide short- or mid-term harm reduction benefits for both successful and unsuccessful participants. Findings were limited by the paucity of studies, their observational nature, and heterogeneity in the features of the different national campaigns, which would probably gain in enhanced internationalization.
\end{abstract}

Keywords: Dry January, One-month abstinence, Alcohol abstinence, Abstinence campaigns

\section{Introduction}

Alcohol consumption is ingrained in the cultural habits of many countries, in particular in "Western" countries. However, an accumulating body of evidence indicates that both the amount and frequency of alcohol use are directly associated with an increased mortality resulting from various medical risks, including cancer [1], alcoholrelated liver diseases [2], stroke, coronary disease, heart failure, hypertensive disease, and aortic aneurysm [3].

*Correspondence: jdeternay@gmail.com

${ }^{1}$ Service d'Addictologie, Hôpital Édouard Herriot, Hospices Civils de Lyon,

5, Place d'Arsonval, Pavillon K, 69003 Lyon, France

Full list of author information is available at the end of the article
Public health strategies thus aim to promote an overall reduction in alcohol use among the general population.

In this respect, public health campaigns, challenging the general public to temporarily stop alcohol consumption, have been spreading over recent years, as it has also been the case regarding tobacco consumption with the emergence of national and international contests for smoking cessation since the 1980s [4], and of national campaigns, such as the "Stoptober" in the UK since 2012 that promotes a cessation of tobacco smoking for at least 28 days [5]. Temporary alcohol abstinence campaigns aim to promote behavioral changes and general health improvements among participants, which can involve many dimensions of health, including improved sleep, original author(s) and the source, provide a link to the Creative Commons licence, and indicate if changes were made. The images or other third party material in this article are included in the article's Creative Commons licence, unless indicated otherwise in a credit line to the material. If material is not included in the article's Creative Commons licence and your intended use is not permitted by statutory regulation or exceeds the permitted use, you will need to obtain permission directly from the copyright holder. To view a copy of this licence, visit http://creativecommons.org/licenses/by/4.0/. The Creative Commons Public Domain Dedication waiver (http://creativeco mmons.org/publicdomain/zero/1.0/) applies to the data made available in this article, unless otherwise stated in a credit line to the data. 
weight loss, increased physical activity, or enhanced quality of life. As such, adding to these elements the fact that these campaigns do not necessarily promote a complete cessation of alcohol consumption in the long term, but rather encourage drinkers to question their relationship with alcohol and its consequences on their health, they can be conceived as harm reduction programs applied to the general population. In practice, however, temporary abstinence campaigns have generally been implemented at a national level, and the way they have been set up may thus largely differ between countries. In particular, the time frame of the abstinence period challenge can be very variable, depending on the program. In some programs, this abstinence period is quite long, e.g., three months in the Buddhist Lent Dry Campaign abstinence in Thailand [6], or even twelve months [7]. However, the longer the targeted abstinence period is, the more the participants' characteristics may differ from the general population participating in shorter abstinence periods. For example, $95 \%$ of the people participating in the Australian Hello Sunday Morning (HSM) program, an online Australian program promoting alcohol abstinence for three or twelve months, reported a harmful alcohol use before engaging in the program [7].

By contrast, the most widespread prevention initiatives that promote temporary alcohol cessation within the general population consist of one-month-long abstinence campaigns (OMACs). This is the case of one of the most popular of these programs, the Dry January challenge, launched in 2013 in the UK ("Dry January | Alcohol Change UK") [8]. Similar January OMACs now exist in Quebec ("Défi 28 jours sans alcool"), France ("Dry January | Le défi de janvier !"), and in the Netherlands ("IkPas") [9], while other months of the year have been chosen in other countries, i.e., February in Belgium ("Tournée Minérale-Een maand zonder alcohol") [10] and New-Zealand from 2011 to 2015 ("FebFast NZ | NZ Drug Foundation"), and November in Hungary ("Száraz November") [11]. In Australia, three campaigns have coexisted for ten years, the first, Dry July, started in 2008 and still exists ("Go Dry this July") [12] while the second, Febfast was established in 2007 in Australia and in 2011 in New Zealand [14] and the third, Ocsober, was discontinued in 2019 after having been running for ten years ("Life Education") [13]. Another common feature of OMACs is that participants can sign up on social media, and thus receive and post-supportive messages, which makes them belong to online communities that may foster their personal efforts [15]. Other inconstant features are the fundraising aspect of some campaigns (in particular in the Australian programs) where the participants can buy one-day leave passes if they wish to withdraw from the program only for one day.
In this review, we addressed the harm reduction benefits of OMACs, that is, the features of participants, the rates and predictors of success, i.e., completing the abstinence challenge, and the health benefits reported by participants, including those who did not fulfill the challenge. The aim of this review was to provide a state-ofthe-art of the demonstrated evidence regarding the harm reduction benefits of OMACs, but also to determine which additional research questions should be addressed in the upcoming years, and which populations should be more specifically targeted in future OMACs, in particular those who could currently not been reached by the existing programs.

\section{Methods}

We conducted a systematic search in PubMed, ScienceDirect and PsycInfo from inception to 30/08/2021 using the following keyword algorithm: ("Dry January" OR "Dry July" OR "Dry November" OR "Ocsober" OR "IkPas" OR "Febfast" OR "la Tournée minerale" OR "défi 28 jours" $O R$ "temporary abstinence") AND alcohol. The title and abstract of the records identified through the search algorithm were independently reviewed by two authors (JdT and PL). Disagreements were resolved by two senior authors (BR and MN). Additional records could be added using the reference list of the included articles and the grey literature (World Health Organization database, Virtual health database, OpenGrey database, available reports from websites of OMACs).

The studies included for review had to be written in English, have a quantitative research method, and report data on one of the following items: (1) the characteristics of individuals participating in the program(s), (2) the proportion of participants who reached the target of onemonth abstinence, (3) the individual predictive factors of success or failure for completing the OMAC, and (4) the outcomes reported by the participants. We chose to focus only on epidemiological studies providing quantitative data and pertaining to the general population, studies with a local or regional focus were therefore excluded, as were those with experimental research design, studies focusing on alcohol abstinence campaigns longer than one-month, qualitative studies, as well as letters or articles providing no original data.

For each study, the following data were extracted in calibrated form: authors' name, publication year, country, publication type, study methodology, name of the abstinence challenge and year of the event, main results and others findings. The characteristics of each study were extracted by two authors (JdT and PL), and disagreements were resolved by two senior authors (BR and $M N$ ). For each study, the descriptive results corresponding to the objectives of the review (see above) were reported 
into the Results section. All authors participated in the appraisal and synthesis of the results.

\section{Results}

The database search identified 222 records (PubMed, ScienceDirect, PsycInfo), and 132 records were identified in grey literature. Thirty-two duplicates were removed. The title and abstract of 322 individual records were screened, 309 of which were irrelevant and excluded. The 19 remaining records included seven studies and the 12 Dry July Annual reports that underwent full-text examination. One of the studies was then excluded because of its experimental research design [16] as well as five Dry July Annual reports providing no answer to any of the four research questions. Six studies [17-22] and seven
Dry July Annual reports [23-29] were finally included for the review (Fig. 1). The six studies were published between 2016 and 2021, five of them referred to Dry January [17-20, 22], and one pertained to Febfast 2012 [21]. Characteristics of the reviewed studies and reports can be found in Table 1.

\section{Characteristics of individuals participating in these programs}

Subjects aged between 25 and 35 years represented the highest proportion of participants in the Dry July campaign in 2010 (38.5\%), 2011 (34.0\%) and 2014 (38.0\%) [23, 24, 27], respectively. Compared to a control group of non-participating alcohol users, registrants to Dry January and Febfast were found to be more likely female

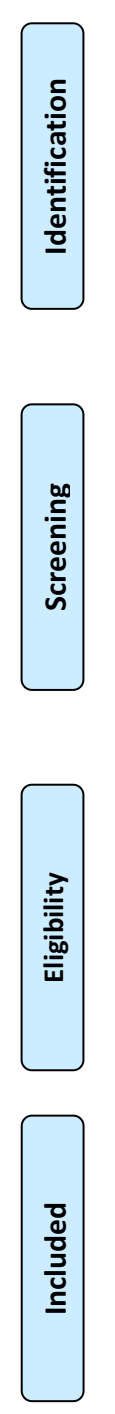

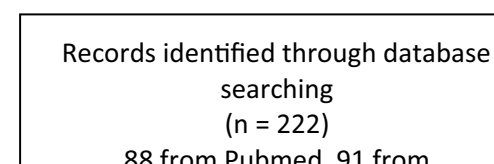

88 from Pubmed, 91 from ScienceDirect, 43 from Psyclnfo

\section{Additional records identified in grey literature ( $n=132) 118$ from Virtual Health Library, 12} Annual Reports from the Dry January website, 2 reports from the Febfast website

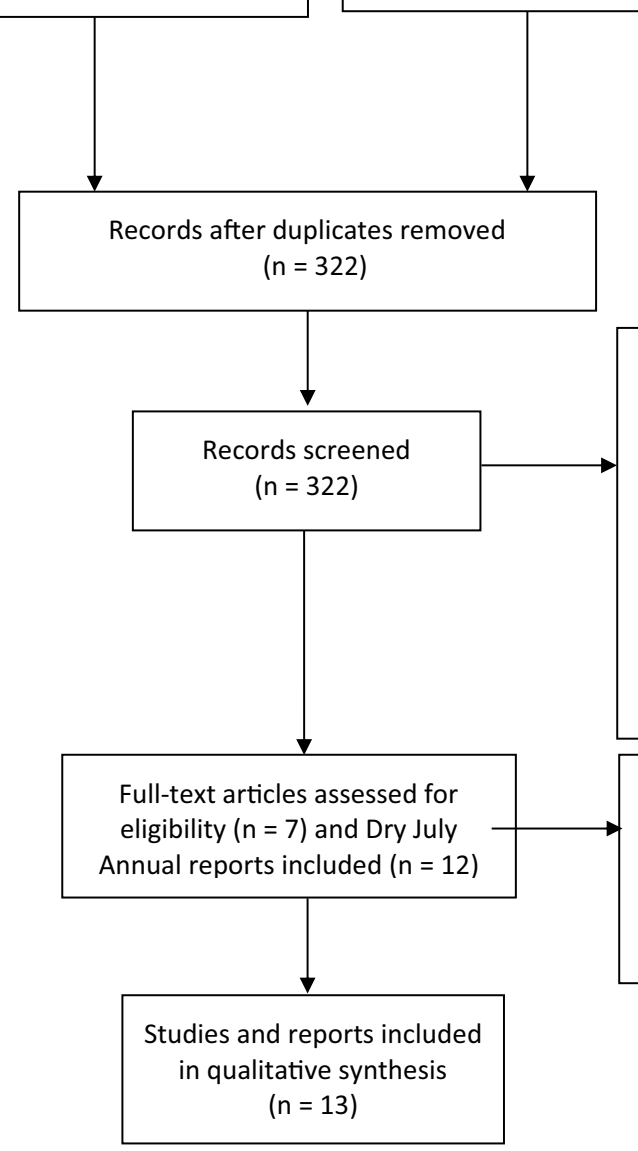

303 records excluded

$n=263$ : title irrelevant to the search $n=40$ : exclusion after reading of abstract

- 5 : focusing on abstinence campaigns $>1$ month

- 1: not focusing on any of the four research questions

- 2: qualitative studies

- 17: not abstinence campaigns

- 15: no original data

Full-text articles excluded ( $n=6) 1$ full-text article with experimental design, 5 Dry July Annual reports providing no answer to any of the four research questions.

Fig. 1 Flowchart of reviewed studies from literature search to inclusion in the scoping review 


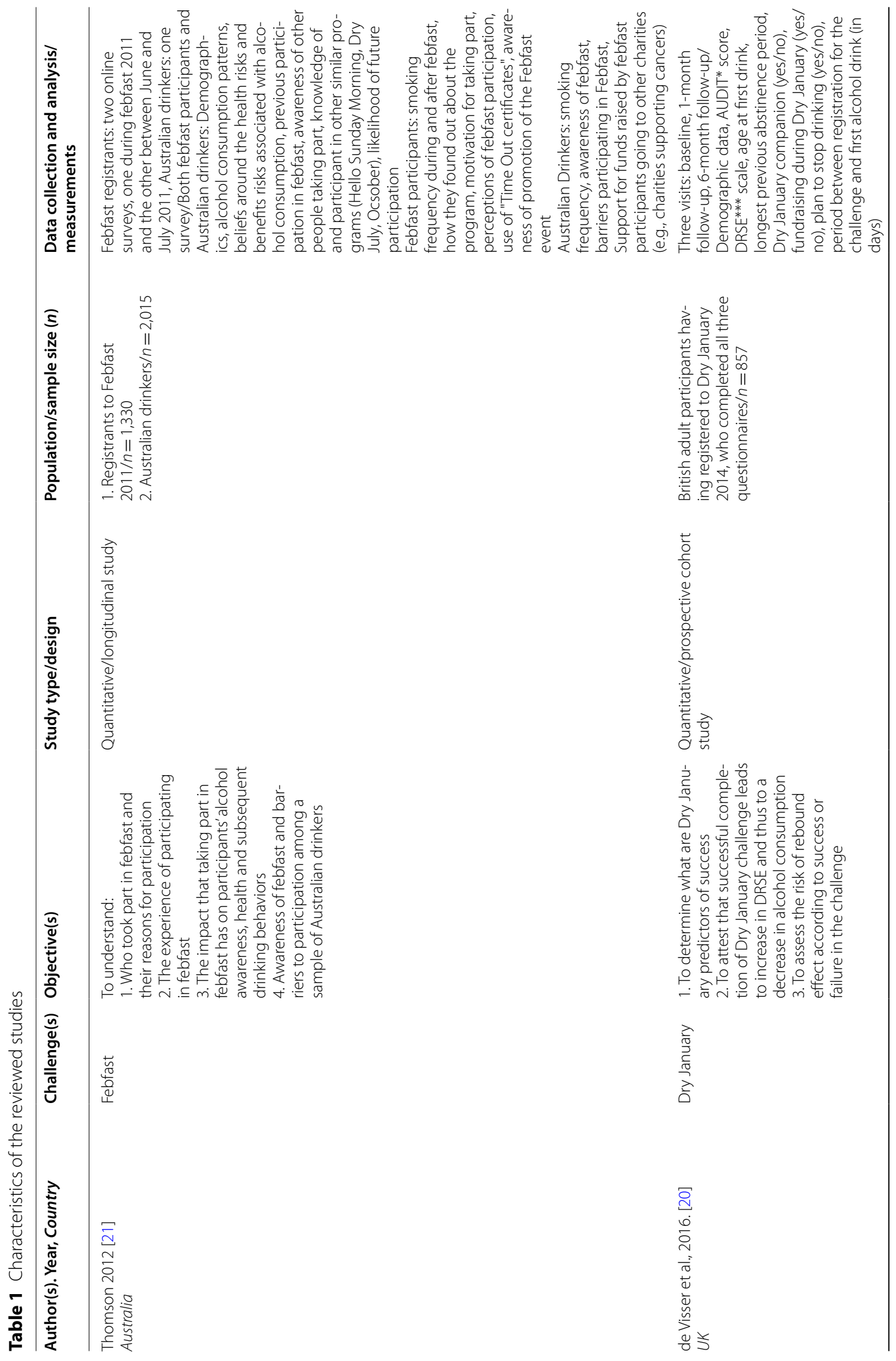




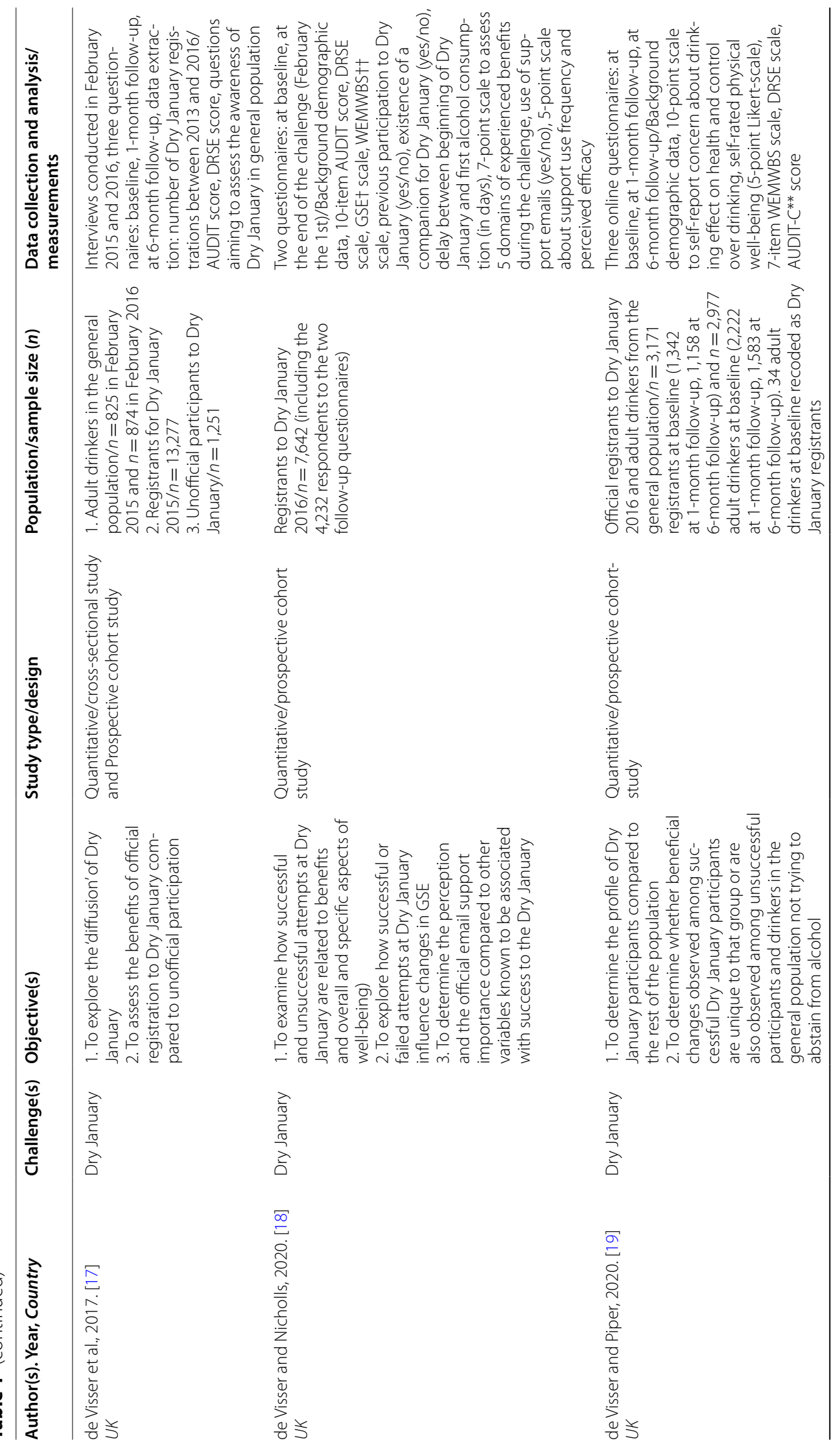




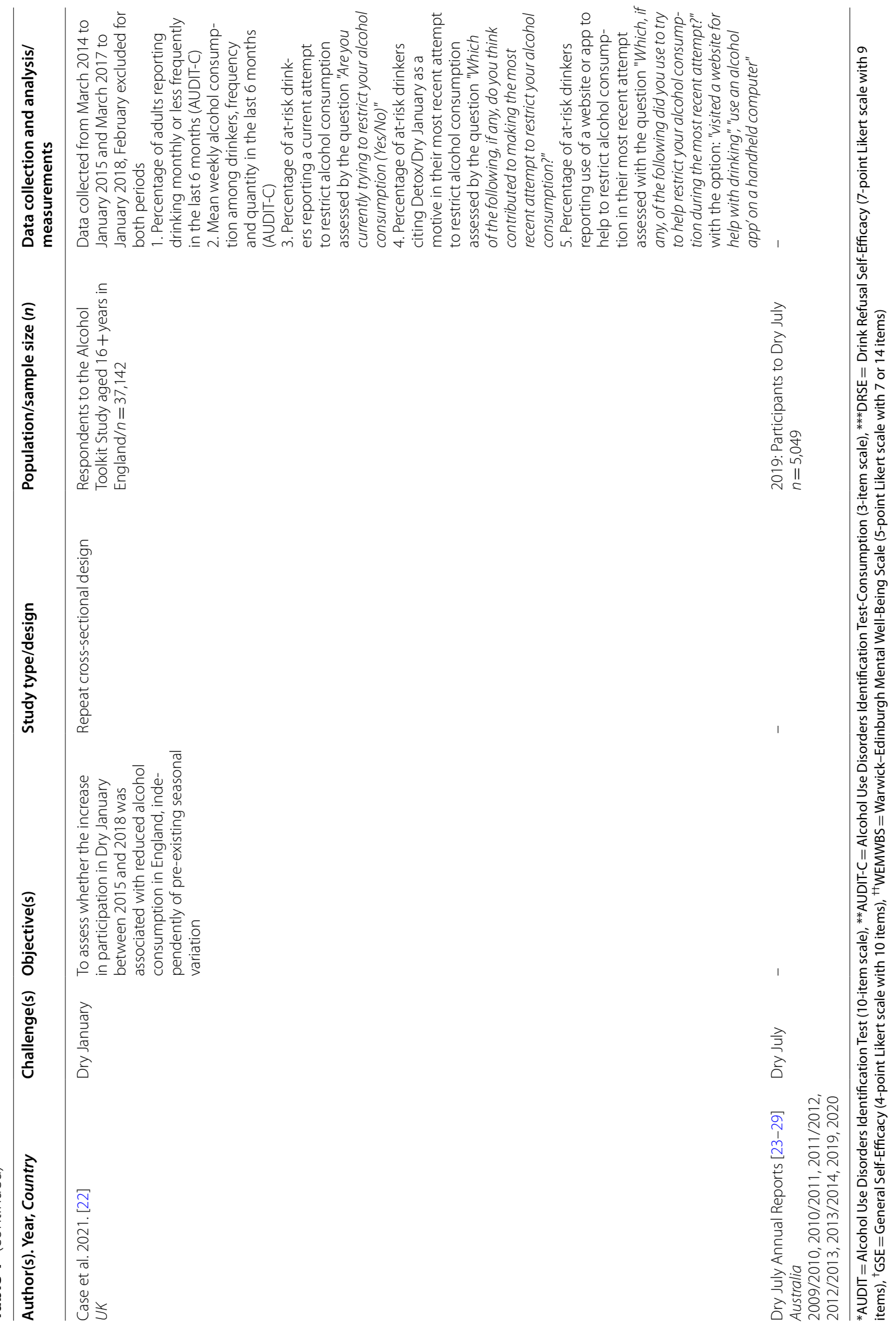


(75.3\%, 95\%CI [72.5; 77.8], vs. 50.9\%, 95\%CI [47.9; 53.9]; $p<0.01)[19,21]$, be working [21], and to have completed university education, $(48.1 \%, 95 \% \mathrm{CI}$ [45.0; 51.2], vs. $37.7 \%, 95 \%$ CI $[34.8 ; 40.6] ; p<0.01)[19,21]$. Registrants also had a higher income [21], a better self-rated physical health, a lower score on the Warwick-Edinburgh Mental Well-being Scale $(3.37,95 \%$ CI [3.32; 3.41] vs. 3.46, 95\%CI [3.41; 3.52], $p<0.01$ ) [30], and they were more concerned about the health consequences of drinking, and about their control over drinking [19]. They were more likely to agree that alcohol is a serious issue for the community, and less likely to believe that there were benefits associated with drinking alcohol [21]. They were also more likely to classify themselves as heavier drinkers [21] and had a higher score on the Alcohol-Use Disorders Identification Test-Consumption (AUDIT-C) [31] (8.47, $95 \%$ CI $[8.27 ; 8.66]$ vs. $5.74,95 \%$ CI $[5.49 ; 6.00], p<0.01)$. They exhibited a lower drink refusal self-efficacy score (DRSE), which is the perceived ability to refuse alcohol in different contexts-emotional, social and opportunistic [32] $(4.30,95 \% \mathrm{CI}[4.21 ; 4.40]$ vs. 5.28 , 95\%CI [5.17; 5.39]; $p<0.01$ ). During Dry January, they were more likely to have tried to increase their physical activity (48.7\% vs. $23.8 \% ; p<0.01)$ or to improve their $\operatorname{diet}(52.3 \%$ vs. $28.2 \%$; $p<0.01$ ) [19] (Table 2).

\section{Success rates}

Between 61 and 64\% [17-20] of registrants reported they had successfully completed Dry January whereas only $30.2 \%$ of the unofficial participants, i.e., participants who had not officially registered on the Dry January application or website, declared having completed it $(p<0.01)$ [19] (Table 2).

\section{Predictive factors of success or failure}

Studies on Dry January found that participants were more likely to complete the program if they had fewer drinks per drinking day $(d=0.21 ; p=0.01)$, lower frequency of drunkenness $(d=0.19-0.36 ; p<0.01)$, a lower AUDIT score $(d=0.26 ; p<0.01,9.80$ vs. $11.48, d=0.24$; $p<0.01)$, higher social $(d=0.21-0.23 ; p<0.01)$, emotional $(d=0.16 ; p=0.02, d=0.23 ; p<0.01)$ and opportunistic DRSE scores $(d=0.18 ; p<0.01)$, greater mental well-being $(d=0.12 ; p<0.01)$, higher general self-efficacy score (i.e., the perceived self-efficacy of being able to adapt and cope with various situations) $(d=0.10$; $p<0.01)$ at baseline, and had read all the supportive emails during the campaign $(V=0.08 ; p<0.01)[18,20]$. Heavier drinkers were more likely to fail to complete the event during Febfast [21]. A similar proportion of males and females reported success (females 62.9\%, males $66.7 \%, p=0.29$ ) [20] (Table 2), but in another study, after adjustment, being a male was an independent predictor of a successful challenge $(\mathrm{OR}=1.46,95 \% \mathrm{CI}[1.35 ; 1.58])$ [18].

\section{Outcomes reported by participants}

Twenty-five percent of the Febfast registrants reported giving up alcohol for a month was difficult or very difficult, especially younger participants and participants with heavier drinking patterns [21]. Dry January registrants had a higher DRSE score at 1-month and 6-month follow-up when they were successful (baseline: 4.27, 95\%CI [4.14; 4.40], 1-month follow-up: 4.86, 95\%CI [4.73; 4.98], 6-month follow-up: 4.83, 95\%CI [4.69; 4.96]) [19]. This was also the case for those who were unsuccessful at 1 month (baseline: 4.63, 95\%CI [4.45; 4.82], 1-month follow-up: 5.04, 95\%CI [4.88; 5.21]), and there was a trend toward this at 6 months $(4.94,95 \% \mathrm{CI}[4.76 ; 5.12])$ [33]. The successful participants' DRSE score increased in all three dimensions, whereas only the social and emotional dimensions increased for the unsuccessful participants [20]. No significant change in DRSE was found among unofficial participants [17].

Among the successful registrants, there was a decrease in the AUDIT-C score from baseline $(8.89,95 \%$ CI [8.65; 9.12]), to the 6-month assessment $(6.72,95 \% \mathrm{CI}[6.32$; 7.07]) [19], as well as significant reductions in the number of drinking days per week $(d=0.53 ; p<0.01)$, number of drinks per drinking day $(d=0.25 ; p<0.01)$, frequency of drunkenness $(d=0.40 ; p<0.01)$ at 6 -month follow-up [20]. The same improvements were found among unsuccessful registrants (AUDIT-C at baseline: 6.82, 95\% CI [6.37; 7.27], at 6-month follow-up: 6.18, 95\%CI [5.76; 6.59], drinking days per week $d=0.45 ; p<0.01$, drinks per drinking day $d=0.18 ; p<0.01$, frequency of drunkenness $d=0.39 ; p<0.01)[19,20]$. However, unsuccessful registrants were more likely to report an increased frequency of drunkenness after Dry January compared to those who were successful (14.6\% vs. $8 \%$; $p<0.01)$ [20].

Only successful Dry January registrants had a higher general self-efficacy score at 1-month follow-up (3.19 at baseline vs. 3.25 at follow-up, $p<0.01$ ) [18].

The Warwick-Edinburgh Mental Well-being Scale score was higher at 1-month follow-up for all participants $(d=0.34, p<0.01)$ [18] and 6-month follow-up for both successful (baseline: 3.40, 95\%CI [3.34; 3.47], follow-up: $3.68,95 \% \mathrm{CI}[3.62 ; 3.74]$ ) and unsuccessful (baseline: 3.37, 95\%CI [3.28; 3.47], follow-up: 3.49, 95\%CI [3.39; 3.58]) registrants to Dry January [19]. Self-rated physical-health was greater at both 1-month and 6-month follow-up for successful registrants (baseline: 3.26, 95\%CI [3.17; 3.35], 1-month follow-up: 3.47, 95\%CI [3.39; 3.56], 6-month follow-up: 3.47, 95\%CI [3.39; 3.56]) [19]. Participants to Dry July reported having changed their diet (2012: 36\%, 2013: 22\%), and having increased their current exercise 
program (2012: 36\%, 2013: 22\%) at the mid-year health check $[25,26] .21 \%$ of 2019 Dry July participants reported feeling healthier [28].

Registrants reported other benefits of Dry January such as savings (63\%), improved sleep (56\%), more energy (52\%), better health (50\%), weight loss (38\%). Improvement in all five of these domains was greater among successful participants (savings $d=0.13 ; p<0.01$, sleep $d=0.15 ; p<0.01$, energy $d=0.14 ; p<0.01$, health $d=0.12 ; p<0.01$, weight $d=0.24 ; p<0.01$ ) [18] (Table 2). The most commonly reported benefits during Febfast were also savings (52.2\%), improved sleep (40.5\%), weight loss (38.1\%) and improved overall health (35.3\%) [21]. 46.5\% of Febfast registrants reported a reduction of their tobacco consumption during the event [21].

In the UK, odds of at-risk drinkers reporting a current attempt to restrict alcohol consumption was significantly higher in January compared to the other months $(\mathrm{OR}=1.46,95 \% \mathrm{CI}[1.25 ; 1.70])$, as were the odds of at-risk drinkers citing Dry January as a motive in their most recent attempt to restrict consumption $(\mathrm{OR}=2.29$, 95\%CI [1.62;3.22]) [22].

\section{Discussion}

Each year, OMACs attract an increasing number of participants. For example, even if it still represents less than one percent of the Australian adult population in 2019, 44,000 people officially registered for Dry July [28], while they were 16,787 in 2016 and 9,532 in 2010 [34]. Regarding Dry January, 4,000 people participated in the 2014 campaign while they were 3.9 millions in 2020, that is, approximately $7.5 \%$ of the UK adult population $[35,36]$. However, for ensuring the continued success of such campaigns, it is important to inform participants whether these programs meet harm reduction objectives. This review thus aimed to determine the profile of participants in the different national one-month abstinence campaigns, to estimate the rates and factors of success, and to explore the associated subjective benefits in participating in or completing the challenge.

Based on the studies pertaining to Dry January, it seems that those taking part in the challenge were more likely to be heavier drinkers, more concerned about their health, and had higher levels of incomes and education. The latter aspects are consistent with those reported elsewhere: the concern for healthy behaviors is more developed among individuals with higher education and incomes $[37,38]$. However, this relationship is probably mediated, at least partially, by the overall level of education received, including during school years, suggesting that sustained and universal health education programs could help to bridge this gap [39]. The finding that females were more attracted in participating in abstinence campaigns is possibly in line with the fact that females are in general more concerned about health-related behaviors [40]. However, being a male led to better chance of successfully complete the abstinence campaign, specifically for campaigns promoting restriction of alcohol use. These results may reflect cultural differences across gender, with respect to alcohol use and alcohol-related representations [41].

Completing the one-month abstinence challenge was found to be associated with lower drinking patterns and better psychosocial functioning at baseline. Thus, it is interesting to note that those participating in the abstinence campaigns had more elevated drinking patterns compared to the non-participating alcohol users, whereas those achieving the challenge had lower drinking patterns compared to those who did not. Another important factor of success was the registration and active participation in social media communities. This is in line with the overall finding that interactive social media on the Internet can be a very effective tool to change health behaviors in the general population [42]. There may be some biases in this finding as participants who registered on social communities might be the most motivated ones, which could explain a better success in achieving the challenge. However, sharing the experience and the difficulties encountered during of a long time period of alcohol abstinence on a virtual community was designated as the most efficient strategy to successfully reach the abstinence goal during the online HSM program [7]. In this program, other strategies which were reported to be efficient to abstain from alcohol include the engagement in alcohol-free activities, the use of non-alcoholic beverages instead of alcohol, support from family and friends, and anticipation of social events [7]. On the contrary, anxiety, stress, negative emotions, social pressure to drink, loneliness, boredom, and no social support were reported as barriers to maintain alcohol abstinence [7]. Considering those dimensions as potential factors for success or failure in national one-month abstinence campaigns would be relevant in further studies.

Many participants in OMACs reported subjective improvements in health, including improved sleep, weight loss, an increased "energy". An important finding is that Dry January participants also reported to have tried to increase their physical activity and to improve their diet, which was also reported by Dry July participants during the mid-year health check. This may suggest that these campaigns are actually not merely alcoholfocused for many participants, and might consist for them to a health-focused month, in particular when it is the first month of the year immediately after the end of year celebrations. This finding might have important implications for the evolution of the communication 


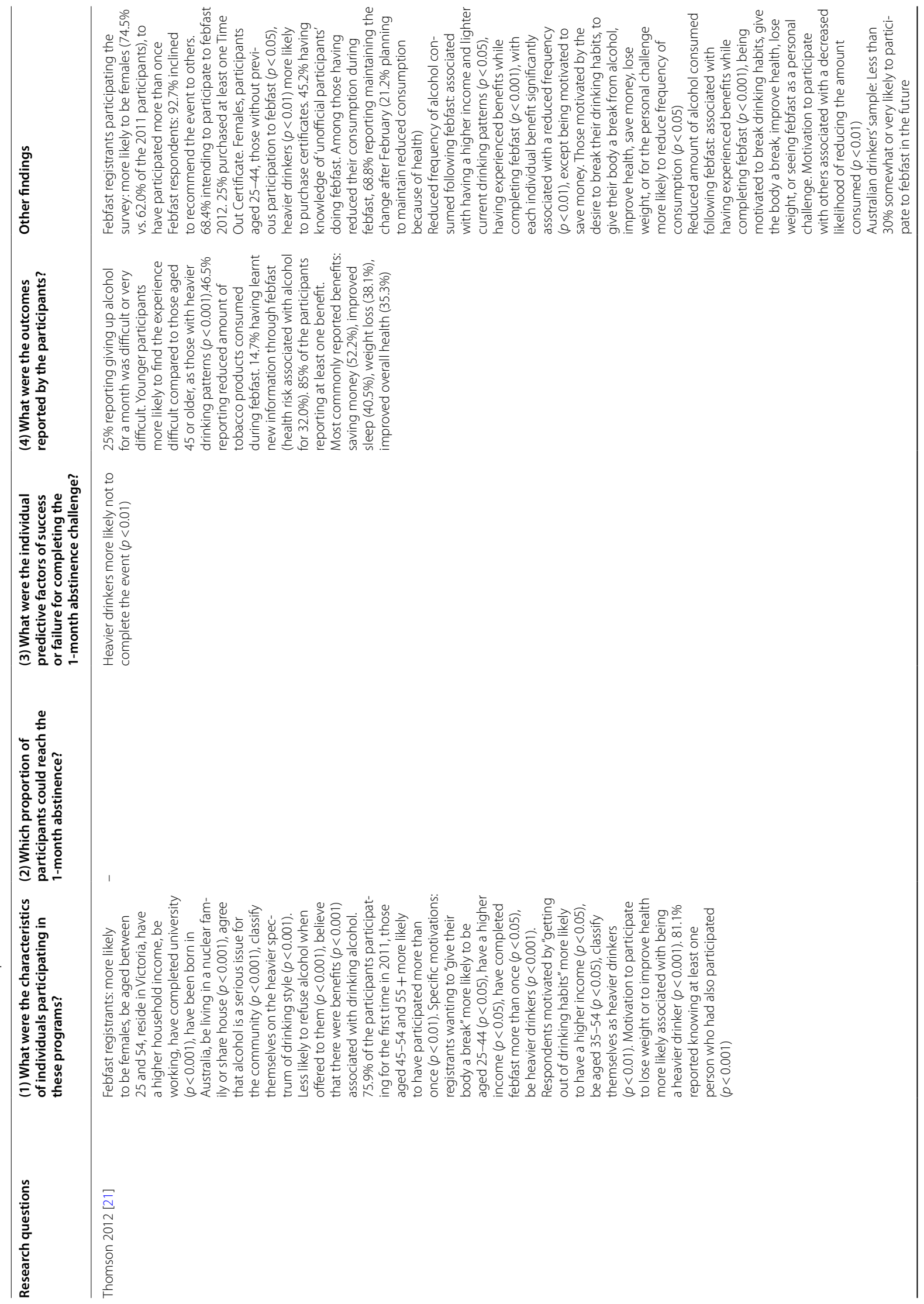




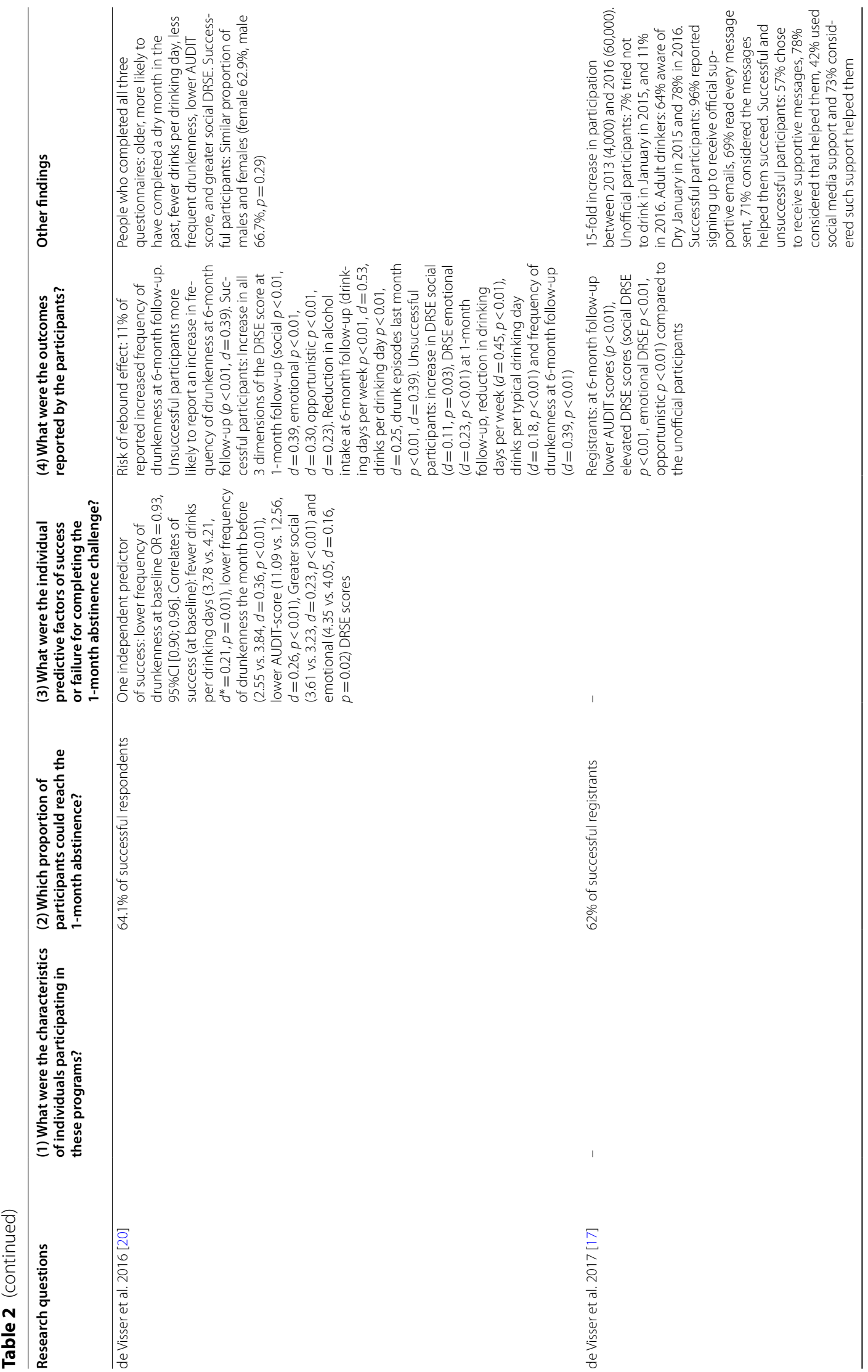




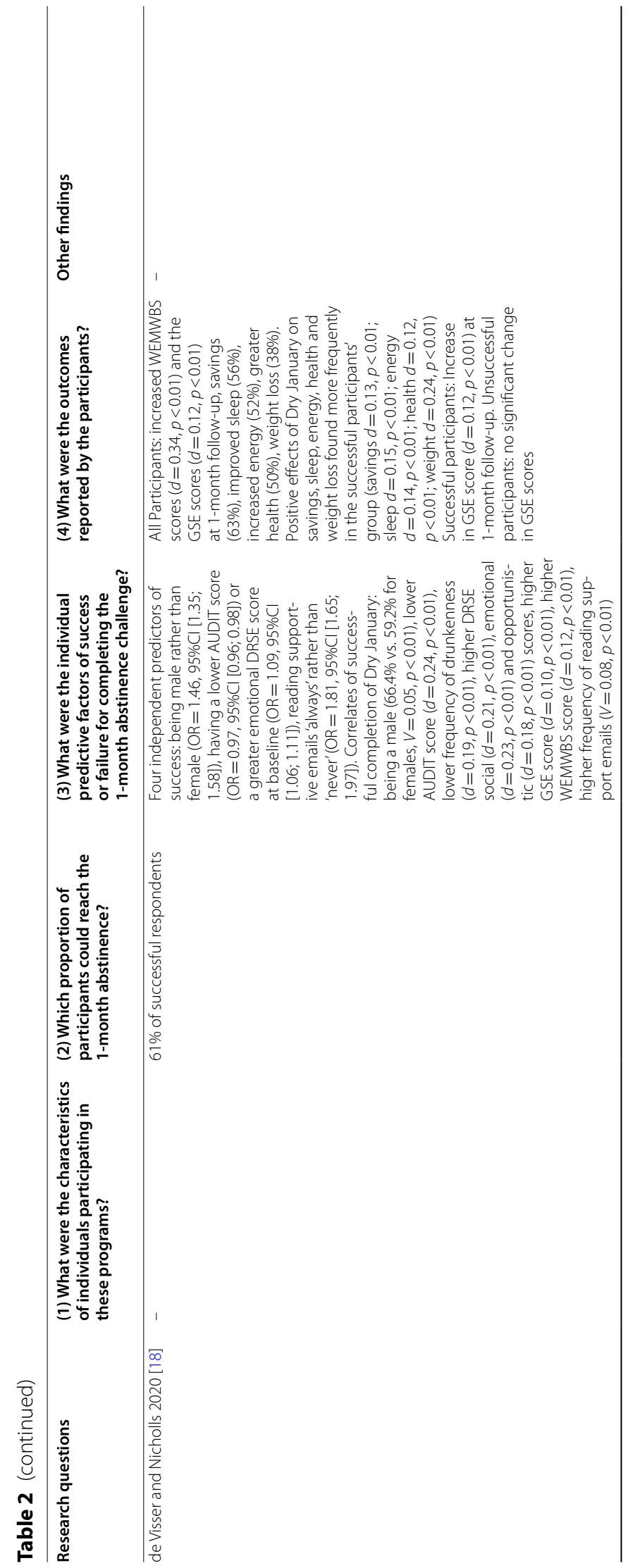




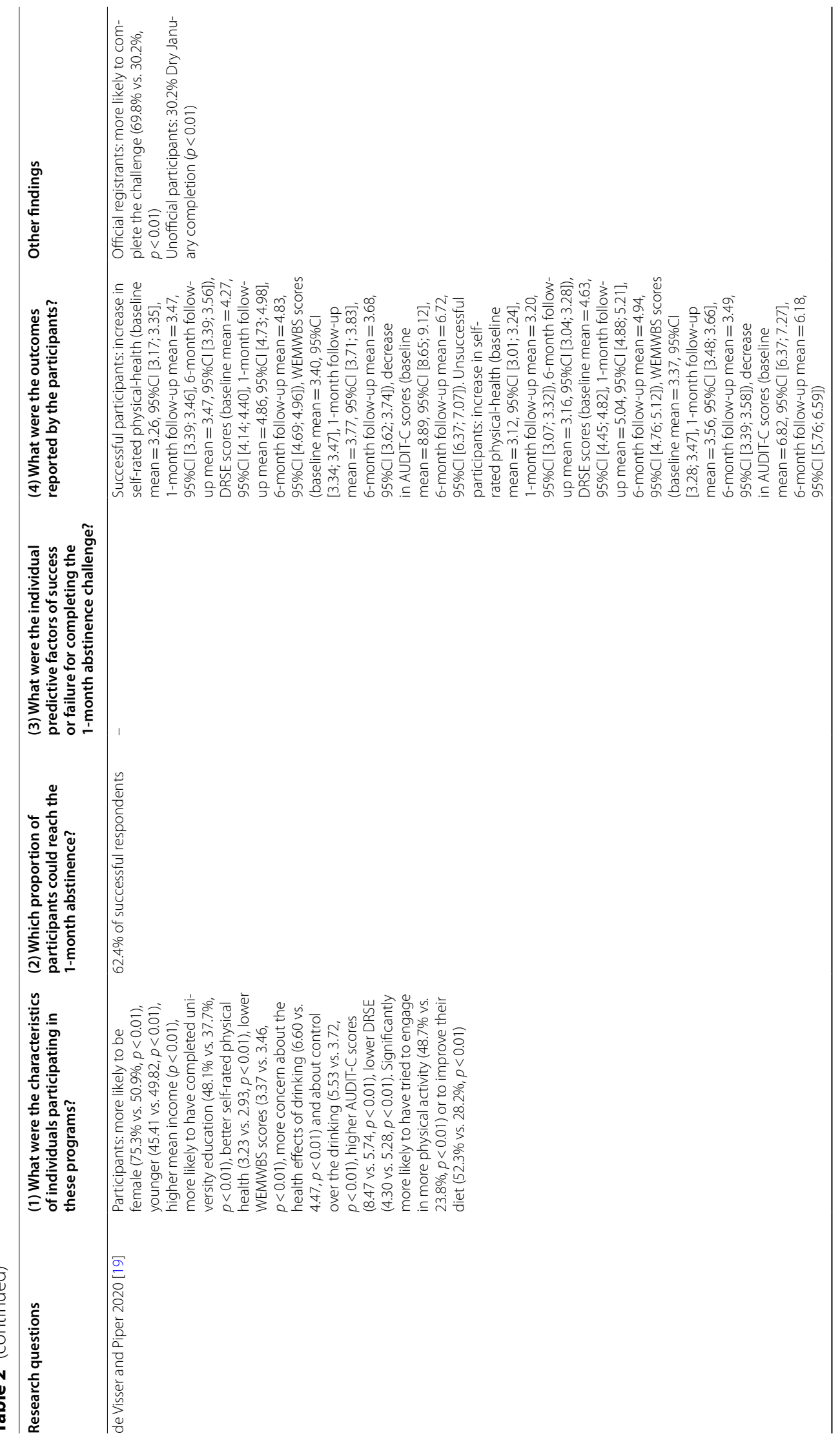




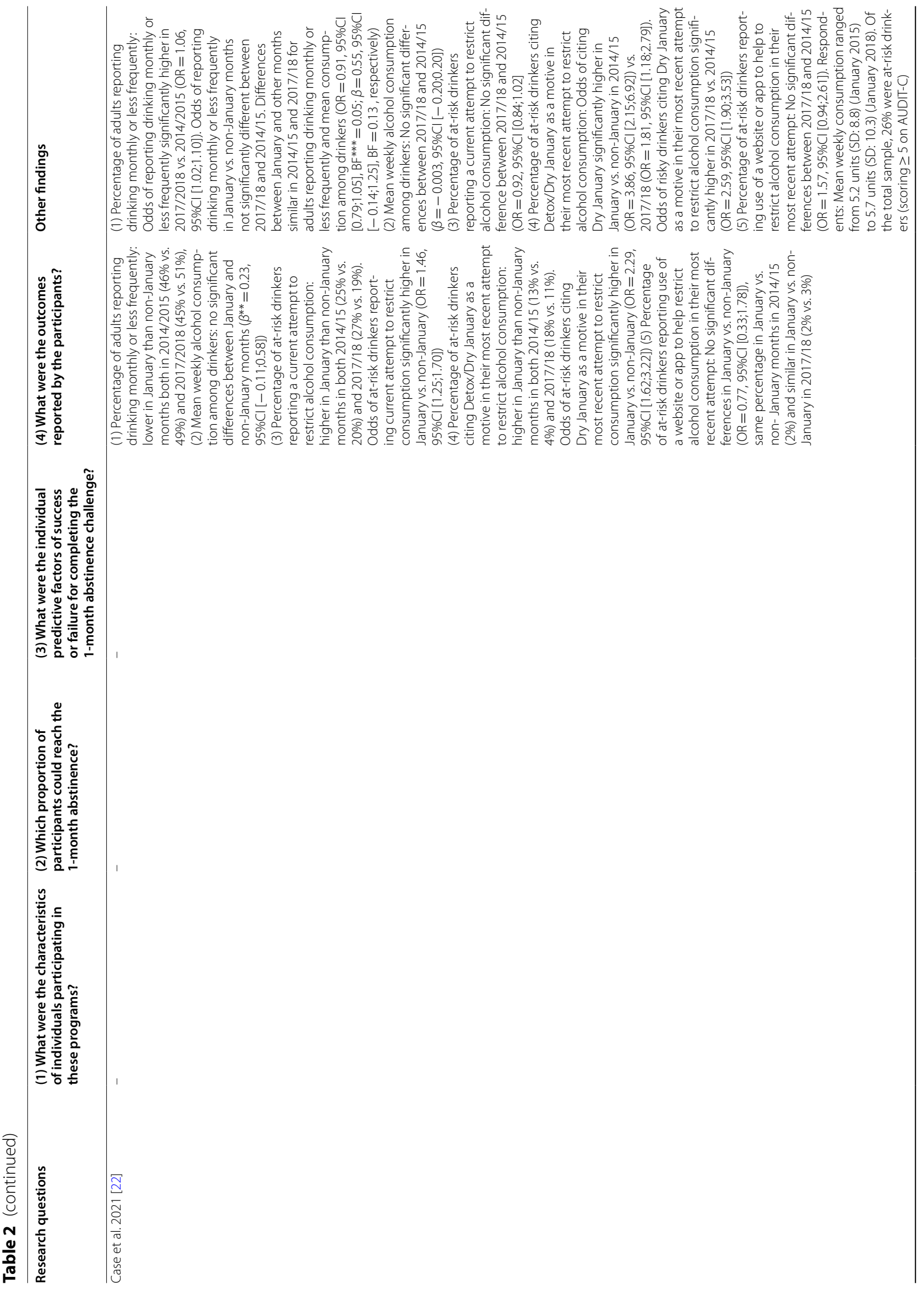




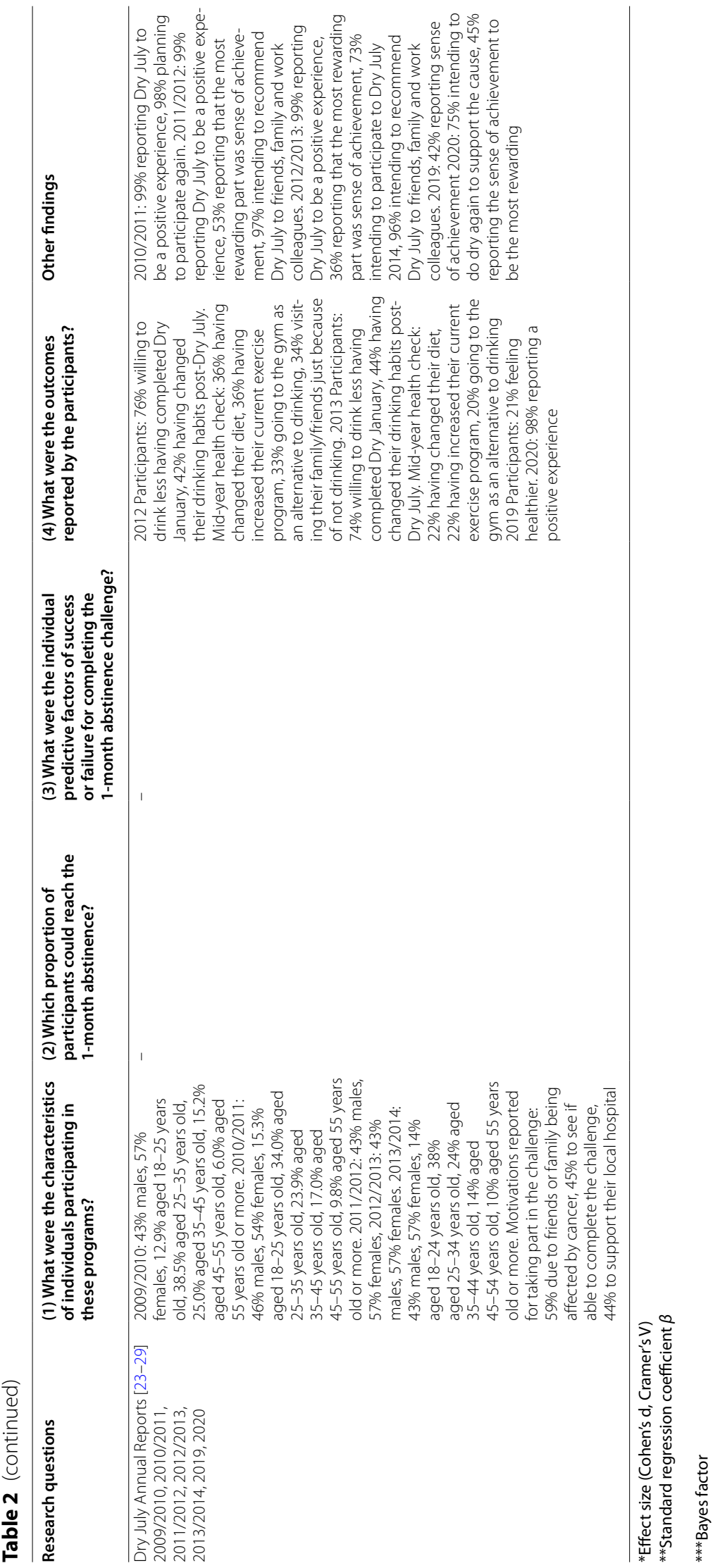


around these prevention campaigns. Moreover, improvement in health after one-month alcohol abstinence was objectively demonstrated for several parameters in a study with drinkers drinking above national guidelines where one-month alcohol abstinence led to a decrease in blood pressure, decrease in circulating concentrations of cancer-related growth factors, decrease in insulin resistance and weight reduction compared to the non-abstinent group [43].

Several limitations of this review should be addressed. Firstly, the majority of the available data comes from the UK Dry January initiative, which may restrain the generalizability of the conclusions. Secondly, there is a general paucity of studies for this kind of campaigns, and those available were non-randomized, but undertaking randomized studies in general prevention campaign is difficult, although some argue that it is feasible and that it should be done more often [44]. Moreover, we chose to focus only on the one-month abstinence campaigns, whereas other similar events involved a longer duration $[6,45]$. However, we hypothesized that the responses to the questions addressed in this review were different for longer abstinence periods, including the profile of the participants, the rates and factors of success, and the subjective benefits of stopping alcohol. For instance, a 3-month abstinence campaign stands during the Buddhist-Lent period in Thailand, with factors being associated with successful alcohol abstinence including drinking frequency before the campaign but also religion and making a public commitment [45], and thus, parallels can hardly be made with these types of campaigns. Another limitation is that we only focused on the literature written in English and it's therefore possible that we missed some data. As OMACs are far more recent in French speaking countries, we chose not to search for articles written in French language, assuming no data would yet be available. Moreover, if we had considered not English-only literature, it would have been methodology and deontologically required to explore all the languages concerned, including Dutch or Hungarian, which would have required additional skills and time for what we deemed as a probably limited result. Last, there was an important heterogeneity between the different national campaigns, their name, their goal including collecting funds for charities such as in Dry July, their overall organization, the place of social media, the chosen month for the campaign, and the local cultural differences regarding alcohol use and alcohol-related representations.

In order to increase the interest of the media and the general public in this kind of campaigns, it could be relevant to harmonize internationally the OMACs and to launch them simultaneously in neighboring countries.
International discrepancies might persist though, at least between the two hemispheres, as these campaigns are generally set up during the winter. Furthermore, although individual factors of success and failure have been investigated in the UK Dry January challenge, barriers encountered and strategies implemented by participants to achieve success are yet to be identified, for instance the impact or use of societal factors including support by public authorities, as well as social support provided by relatives, social media or online communities as the ones existing in the HSM program. At last, a better understanding of the different profile of participants in the future may lead to improvement in communication strategies and digital tools of alcohol abstinence campaigns.

A remaining theoretical question is whether OMACs may be formally related to harm reduction policies. Originally, the harm reduction approach targeted people who used illicit drugs, and were more focused on reducing harms than promoting an overall reduction in the level of use [46]. However, in practice, harms are generally related to the frequency and average level of use and it is particularly relevant for alcohol, for which the indubitable related harms [47] are considered to be largely dose-related [48, 49]. Consequently, durably reducing the level of alcohol use is associated with a subsequent reduction in alcohol-related harms, either in populations with AUD, as well as in the general population $[43,50]$. For these reasons, OMACs are generally considered as belonging to harm reduction policies $[22,51]$, even if they sensibly differ from the original meaning of the concept [52].

In conclusion, the present review identified some useful insights into OMACs, which offers a more comprehensive understanding of the effects of these interventions and of their harm reduction potential in the general population, but it also emphasizes the need for further researches to fill the remaining gaps about their objective benefits, the strategies deployed by the participants throughout the whole challenges, and the practical ways to reach an extended part of the population.

\section{Acknowledgements \\ We gratefully thank Mr. Philip Robinson for providing language help.}

\section{Authors' contributions}

$\mathrm{BR}, \mathrm{PM}, \mathrm{PL}$ and JdT designed the research. PL and JdT analyzed the data. BR, PL and JdT wrote the manuscript. MN, PM and AB edited the manuscript. All authors read and approved the final manuscript.

\section{Funding}

This research did not receive any specific grant from funding agencies in the public, commercial, or not-for-profit sectors.

Availability of data and materials Not applicable. 


\section{Declarations}

Ethics approval and consent to participate

Not applicable.

\section{Consent for publication}

Not applicable.

\section{Competing interests}

The authors declare that they have no competing interests.

\section{Author details}

${ }^{1}$ Service d'Addictologie, Hôpital Édouard Herriot, Hospices Civils de Lyon, 5, Place d'Arsonval, Pavillon K, 69003 Lyon, France. ${ }^{2}$ Research on Healthcare Performance (RESHAPE), INSERM U1290, Hospices Civils de Lyon, Lyon, France. ${ }^{3}$ Hôpital Paul Brousse, AHPH, Université Paris-Sud, Paris, France. ${ }^{4}$ Unité Psychiatrie-Comorbidités-Addictions (PSYCOMADD), APHP, Université Paris-Sud, Paris, France. ${ }^{5}$ Groupe de Recherche sur l'Alcool et les Pharmacodépendances (GRAP), INSERM U1247, Université de Picardie Jules Verne, Amiens, France. ${ }^{6}$ Service Universitaire d'Addictologie de Lyon (SUAL), CH Le Vinatier, Bron, France. ${ }^{7}$ CRNL PSYR2, Inserm U1028, CNRS UMR 5292, Université Claude Bernard Lyon 1, Bron, France.

Received: 29 September 2021 Accepted: 17 February 2022 Published online: 04 March 2022

\section{References}

1. Bagnardi $V$, et al. Alcohol consumption and site-specific cancer risk: a comprehensive dose-response meta-analysis. Br J Cancer. 2015;112(3):580-93.

2. Rehm J, Samokhvalov AV, Shield KD. Global burden of alcoholic liver diseases. J Hepatol. 2013;59(1):160-8.

3. Wood AM, Kaptoge S, Danesh J. Risk thresholds for alcohol consumption: combined analysis of individual-participant data for 599912 current drinkers in 83 prospective studies. Lancet. 2018;391(10129):1513-23.

4. Fanshawe TR, Hartmann-Boyce J, Perera R, Lindson N. Competitions for smoking cessation. Cochrane Database Syst Rev. 2019. https://doi.org/10. 1002/14651858.CD013272.

5. Brown J, Kotz D, Michie S, Stapleton J, Walmsley M, West R. How effective and cost-effective was the national mass media smoking cessation campaign 'Stoptober'? Drug Alcohol Depend. 2014;1(135):52-8.

6. Jirarattanasopha V, Witvorapong N, Hanvoravongchai P. Impact of Buddhist Lent Dry Campaign on alcohol consumption behaviour: a community level study. Health Soc Care Community. 2019;27(4):863-70.

7. Pennay A, MacLean S, Rankin G, O'Rourke S. Hello Sunday Morning: strategies used to support temporary alcohol abstinence through participation in an online health promotion program. Heal Promot J Aust. 2018;29(3):321-7.

8. Dry January | Le défi de janvier ! https://dryjanuary.fr/. Accessed 10 Apr 2021

9. IkPas. https://ikpas.nl/. Accessed 10 Apr 2021.

10. Tournée Minérale. https://www.tourneeminerale.be/nl/over-tourneeminerale. Accessed 10 Apr 2021.

11. Száraz November. http://kekpont.hu/szaraz-november/. Accessed 10 Apr 2021

12. Go Dry this July. https://www.dryjuly.com/. Accessed 10 Apr 2021.

13. Life Education. https://www.lifeeducation.org.au/. Accessed 10 Apr 2021.

14. NZ Drug Foundation. FebFast New Zealand. https://www.drugfounda tion.org.nz/news-media-and-events/five-wonderful-years-of-febfast/. Accessed 10 Apr 2021.

15. Ballard J. What is Dry January? Br J Gen Pract. 2016;66(642):32.

16. Albertella L, Vd Hooven J, Bovens R, Wiers RW. Reward-related attentional capture predicts non-abstinence during a one-month abstinence challenge. Addict Behav. 2021;114:106745.

17. de Visser RO, Robinson E, Smith T, Cass G, Walmsley M. The growth of 'Dry January': promoting participation and the benefits of participation. Eur J Public Health. 2017;27(5):929-31.
18. de Visser RO, Nicholls J. Temporary abstinence during Dry January: predictors of success; impact on well-being and self-efficacy. Psychol Health 2020:35(11):1293-305.

19. de Visser RO, Piper R. Short- and longer-term benefits of temporary alcohol abstinence during 'Dry January' are not also observed among adult drinkers in the general population: prospective cohort study. Alcohol Alcohol. 2020:55(4):433-8.

20. de Visser RO, Robinson E, Bond R. Voluntary temporary abstinence from alcohol during "Dry January" and subsequent alcohol use. Heal Psychol. 2016:35(3):281-9

21. Thomson L. Evaluation of the impact of febfast participation Final report. 2012.

22. Case P, Angus C, De Vocht F, Holmes J, Michie S, Brown J. Has the increased participation in the national campaign "Dry January" been associated with cutting down alcohol consumption in England? Drug Alcohol Depend. 2021:227:108938.

23. Dry January Foundation. Dry July annual report 2009/2010. 2010

24. Dry July Foundation. Dry July annual report 2010/2011. 2011.

25. Dry July Foundation. Dry July 2011/2012 annual report. 2012

26. Dry July Foundation. Dry July 2012/13 annual report. 2013.

27. Dry July Foundation. Dry July annual report 2013-2014. 2014.

28. Dry July Foundation. Dry July impact report. 2019.

29. Dry July Foundation. Impact report 2020. 2020.

30. Stewart-Brown S, Platt S, Tennant A, Maheswaran H, Parkinson J, Weich S, et al. The Warwick-Edinburgh Mental Well-being Scale (WEMWBS): a valid and reliable tool for measuring mental well-being in diverse populations and projects. J Epidemiol Community Heal. 2011;65(Suppl 2):A38-9.

31. Bush K, Kivlahan D, McDonell M, Fihn S, Bradley K. The AUDIT alcohol consumption questions (AUDIT-C): an effective brief screening test for problem drinking. Ambulatory Care Quality Improvement Project (ACQUIP). Alcohol use disorders identification test. Arch Intern Med. 1998;158(16):1789.

32. Young RM, Oei TPS, Crook GM. Development of a drinking self-efficacy questionnaire. J Psychopathol Behav Assess. 1991;13(1):1-15.

33. Alcohol Change UK. Dry January. https://alcoholchange.org.uk/get-invol ved/campaigns/dry-january. Accessed 10 Apr 2021.

34. Dry July Foundation. Dry July foundation 2017 report. 2017.

35. Alcohol Change UK. The Dry January story. 2020.

36. Office for National Statistics. Early indicators of UK population size and age structure: 2020. 2021

37. Mackenbach J. Socioeconomic inequalities in health in 22 European countries. N Engl J Med. 2008:358(23):2468-81.

38. Pampel FC, Krueger PM, Denney JT. Socioeconomic disparities in health behaviors. Annu Rev Sociol. 2010;36:349.

39. Hahn RA, Truman BI. Education improves public health and promotes health equity. Int J Health Serv. 2015;45(4):657.

40. Hiller J, Schatz K, Drexler H. Gender influence on health and risk behavior in primary prevention: a systematic review. Zeitschrift Fur Gesundheitswissenschaften. 2017:25(4):339.

41. Holmila M. Gender differences in drinking: why do they still exist? Addiction 2005:100(12):1763-9.

42. Welch V, Petkovic J, Pardo JP, Rader T, Tugwell P. Interactive social media interventions to promote health equity: an overview of reviews. Health Promot Chronic Dis Prev Can Res Policy Pract. 2016;36(4):63.

43. Mehta G, Macdonald S, Cronberg A, Rosselli M, Khera-Butler T, Sumpter $C$, et al. Short-term abstinence from alcohol and changes in cardiovascular risk factors, liver function tests and cancer-related growth factors: a prospective observational study. BMJ Open. 2017;8:e020673.

44. Rosen L, Manor O, Engelhard D, Zucker D. In defense of the randomized controlled trial for health promotion research. Am J Public Health. 2006;96(7):1181.

45. Saengow U. Drinking abstinence during a 3-month abstinence campaign in Thailand: weighted analysis of a national representative survey. BMC Public Health. 2019:19(1):1688.

46. Marlatt GA. Harm reduction: come as you are. Addict Behav. 1996:21(6):779-88.

47. Nutt DJ, King LA, Phillips LD, Independent Scientific Committee on Drugs Drug harms in the UK: a multicriteria decision analysis. Lancet (London, England). 2010;376(9752):1558-65.

48. GBD 2016 Alcohol Collaborators MG, Fullman N, Hawley C, Arian N, Zimsen SRM, Tymeson HD, et al. Alcohol use and burden for 195 countries 
and territories, 1990-2016: a systematic analysis for the Global Burden of Disease Study 2016. Lancet (London, England). 2018;392(10152):1015-35.

49. Rumgay H, Shield K, Charvat H, Ferrari P, Sornpaisarn B, Obot I, et al. Global burden of cancer in 2020 attributable to alcohol consumption: a population-based study. Lancet Oncol. 2021;22(8):1071-80.

50. Munsterman ID, Groefsema MM, Weijers G, Klein WM, Swinkels DW, Drenth JPH, et al. Biochemical effects on the liver of 1 month of alcohol abstinence in moderate alcohol consumers. Alcohol Alcohol. 2018:53(4):435-8.

51. Muckle W, Muckle J, Welch V, Tugwell P. Managed alcohol as a harm reduction intervention for alcohol addiction in populations at high risk for substance abuse. Cochrane Database Syst Rev. 2012. https://doi.org/ 10.1002/14651858.CD006747.pub2.

52. Marlatt GA, Witkiewitz K. Harm reduction approaches to alcohol use: health promotion, prevention, and treatment. Addict Behav. 2002;27(6):867-86.

53. Fondation Jean Lapointe. Défi 28 jours sans alcool. https://www.defi2 8jours.com/. Accessed 10 Apr 2021.

\section{Publisher's Note}

Springer Nature remains neutral with regard to jurisdictional claims in published maps and institutional affiliations.

- fast, convenient online submission

- thorough peer review by experienced researchers in your field

- rapid publication on acceptance

- support for research data, including large and complex data types

- gold Open Access which fosters wider collaboration and increased citations

- maximum visibility for your research: over $100 \mathrm{M}$ website views per year

At BMC, research is always in progress.

Learn more biomedcentral.com/submissions 